\title{
Sprue-like Intestinal Disease
}

\author{
Hugh James Freeman* \\ Department of Medicine (Gastroenterology), University of British Columbia, Vancouver, Canada \\ *Corresponding author: hugfree@shaw.ca
}

Received December29, 2013; Revised January 15, 2014; Accepted January 16, 2014

\begin{abstract}
Recurrent symptoms in well-established celiac disease may result in further clinical evaluation. In most, poor diet compliance is present. Other considerations include an unidentified gluten source, an erroneous initial diagnosis, another or second and superimposed cause for symptoms, or a complication, including collagenous sprue or an intestinal lymphoma. Failure to define an initial gluten-free diet response, however, suggests that celiac disease may not be present. Instead, a distinctive enteropathic process, refractory to diet restrictions, including gluten, is evident. This "sprue-like" intestinal disorder or enteropathy remains unclassified, and probably, represents a heterogeneous entity. Molecular changes suggestive of early clonal expansion of an aberrant population of intraepithelial lymphocytes may be detected in some (with or without a prior gluten-free diet response), and these changes may signify an early or "cryptic" lymphoma. Other newly recognized lymphoproliferative disorders occurring in the setting of celiac disease have been recorded, including hepatosplenic delta-gamma T-cell lymphoma, an indolent CD4+ T-cell lymphoma, particularly in younger males, and large granular lymphocytic leukemia, a possibly treatable disorder characterized by the clonal expansion of T-cells in blood and small intestinal mucosa. Studies using IL-15 blockade in a transgenic mouse model with pathologic features of a sprue-like intestinal disease has led to human clinical trials with encouraging positive results.
\end{abstract}

Keywords: celiac disease, refractory celiac disease, sprue-like intestinal disease, sprue-like enteropathy, unclassified sprue, gluten-sensitive enteropathy, celiac sprue

Cite This Article: Hugh James Freeman, "Sprue-like Intestinal Disease.” International Journal of Celiac Disease 2, no. 1 (2014): 6-10. doi: 10.12691/ijcd-2-1-3.

\section{Celiac Disease}

Celiac disease (also termed gluten-sensitive enteropathy or celiac sprue) is a gluten-dependent disorder of the small intestine that occurs in genetically-predisposed individuals and results from a complex immune-mediated reaction to specific gluten-peptides in wheat and other grain products $[1,2]$. The precise precipitating event is not known. Key elements in the clinical diagnosis include demonstration of an enteropathic process, traditionally using mucosal biopsies from the proximal small intestine, followed by documentation of a treatment response to a gluten-free diet [3].

Usually, after initiation of a gluten-free diet, diarrhea resolves and weight gain occurs. Pathological changes in the small bowel normalize, initially in distal intestinal sites of involvement, and later, sometimes only after prolonged periods (even months to years), in the proximal duodenum [4]. Indeed, some investigators have reported that this may require extended periods, particularly the elderly [5].

Serological studies have estimated that up to $1 \%$ of screened individuals, perhaps more, are at risk for development of celiac disease. Greater detection has occurred in recent years due to more clinical awareness and increased use of screening methods [6,7].

Perhaps, other environmental factors play an important role. These include some newer bio-pharmaceutical agents that can sometimes cause reversible sprue-like intestinal changes, including NSAIDs (eg., sulindac) [8] and, other drugs like olmesarten [9]. In addition, clinically occult celiac disease has appeared after use of novel biological monoclonal agents (eg., ipilimumab) [10]. Finally, in recent decades, a true increase in celiac disease per se may have occurred.

\section{Recurrent Disease}

Recurrence may develop in well-established celiac disease. Usually, this refers to recurrent symptoms, particularly weight loss. Most often, the re-appearance of symptoms is thought to be due to failed compliance with a strict gluten-free diet. However, even the term "glutenfree” may vary for different clinician investigators in different countries, and, sometimes, patient compliance may be difficult to define or fully ascertain. Poor compliance, however, is often clinically obvious, and may even be intentional. For some, limited awareness of foods that contain gluten may make recognition of an offending source difficult. Gluten is ubiquitous, present in pill capsules, communion wafers and a variety of processed food products. Indeed, many processed foods, and even new methods of food processing, are only now emerging. For these, quality control may be limited. Gluten-free foods are costly, often limited in palatability and, especially in developing countries, difficult to obtain. 
Many professionals, including physicians and dietitians, along with support groups and the internet may provide inaccurate information. Some celiacs have limited motivation to follow a strict diet, especially if symptoms are absent or minimal after consumption of glutencontaining foods. Moreover, peer and social pressures, especially for adolescents and young adults, may also be problematic. Finally, trace dietary gluten contamination may well play an important role in both clinical and mucosal recovery process in some celiacs thought to be diet-adherent $[11,12]$.

If symptoms recur, other causes may be responsible. Possibly, the original diagnosis of celiac disease was not correct, particularly if only limited attention was directed to documenting a convincing response to a gluten-free diet. Histological changes in the small intestine are typical, but not specific or diagnostic for celiac disease. Many other conditions may cause similar small bowel mucosal changes [3]. For example, changes in duodenal mucosal biopsies from some with Crohn's disease may be difficult to differentiate pathologically from untreated celiac disease [13]. In recent years, this list has expanded (see Table 1 and Table 2) as new disorders emerge. Of course, none of these other conditions are known to typically respond to a gluten-free diet.

Table 1. Disorders with Biopsy Changes similar to Celiac Disease Sprue syndromes

Collagenous sprue

Mesenteric lymph node cavitation syndrome

Oats-induced villous atrophy

Other protein injury (soy, milk)

Sprue-like intestinal disease (unclassified sprue)

\section{Infectious causes}

Infectious gastroenteritis

Specific infections (eg., strongyloidiasis, giardiasis)

Tropical sprue

Stasis syndrome (contaminated small bowel syndrome)

Whipple's disease

\section{Deficiency states}

Nutrients (zinc, vitamin B12, folic acid)

Kwashiorkor

Immunodeficiency syndromes (congenital, combined, acquired (HIV)

\section{Others}

Intestinal lymphangiectasia

Crohn's disease (duodenum)

Transplant enteropathy (including graft-vs-host disease)

Lymphoproliferative disease (eg., lymphoma)

Macroglobulinemia

Zollinger-Ellison syndrome

Drug-induced small bowel injury*

* NSAIDs (sulindac), Olmesartan, Ipilimumab

Table 2. Causes of Symptoms in Established Celiac Disease Compliance failure with gluten-free diet

Ubiquitous gluten source (eg., pill capsules, processed foods)

Wrong initial diagnosis

Associated or second cause (eg., collagenous colitis)

Superimposed complication (eg., collagenous sprue, lymphoma)

In others, recurrent symptoms may reflect a second or superimposed cause for symptoms. Commonly associated disorders, such as collagenous colitis [14], a poorlydefined "functional" disorder, or a superimposed infectious agent, may be present.
Of particular concern in those with recurrent symptoms is the possibility of a new and complicating disorder associated with celiac disease (eg., collagenous sprue, intestinal carcinoma, lymphoma) [3].

\section{Sprue-like Intestinal Disease (Unclassified Sprue)}

Although celiac disease may be suspected, changes may fail to improve despite strict compliance to a gluten-free diet. Symptoms, such as diarrhea and weight loss, may continue or actually worsen. Repeated small intestinal biopsies may show persistent, usually severe changes. In these, a "treatment-resistant" form of celiac disease could still be present, or a histopathological response may have actually occurred, but only limited to the most distal portion of the small intestine [4]. If a response to a glutenfree diet has never been documented, "refractory celiac disease" should not now be used. For these patients, other labels may be more appropriate, such as "sprue-like intestinal disease” or "unclassified sprue” [15].

These probably represent a heterogenous group, rather than a single entity. Mucosal biopsy changes are often not distinguishable based upon routine microscopic evaluation and staining methods from changes of untreated celiac disease. Others have previously opined that this condition represents a "wastebasket" diagnosis [15]. Some eventually prove to have lymphoma, some do not.

In recent decades, both children and adults have been recorded with persistent diarrhea, sprue-like small intestinal biopsy changes and positive epithelial cell antibodies, specifically anti-enterocyte and anti-goblet cell antibodies. No response to any form of diet exclusion occurs, including a strict gluten-free diet. Some, interestingly, however, also have antibodies to tissue transglutaminase. Possibly, this represents a truly distinctive and novel autoimmune intestinal disorder or group of disorders [16]. Moreover, T-cell lymphoma has also been recorded to complicate this clinical setting $[17,18]$.

\section{Lymphoma in Celiac Disease and Sprue-like Lymphoma}

The relationship between celiac disease and intestinal lymphoma has been especially intriguing. Initially, longterm studies showed that malignant lymphoma may complicate the clinical course of celiac disease [19]. Conversely, in some patients initially presenting with malignant lymphoma, underlying celiac disease [20] with a biopsy-defined histopathological response to a glutenfree diet in non-neoplastic small intestinal mucosa were recorded $[20,21]$.

In others, thought to have celiac disease, clonal expansion of an aberrant intra-epithelial lymphocyte population was described (so-called refractory celiac sprue, “type II disease”) [22,23]. Some molecular markers used to define this entity were reported to reflect an already present, early "cryptic" T-cell lymphoma, as a high subsequent risk for overt histopathologically-defined Tcell lymphoma was recorded [23]. This high risk phenotypic "signature" included an aberrant intraepithelial 
lymphocyte population containing intracytoplasmic CD3 without surface expression of CD3 and CD8 along with a clonally restricted rearrangement of the $\mathrm{T}$-cell receptor (based on immunohistochemical or flow cytometric methods) [22,23]. In some, the gluten-dependent nature of celiac disease was not recorded, perhaps due to a rapidly progressive course. Indeed, in some with lymphoma, dramatic presentations may occur, with free perforation [24]. The histopathological changes in the mucosa, however, may be similar to untreated celiac disease. For these, the term "sprue-like intestinal T-cell lymphoma" was noted [25].

In celiac disease, multiple pathways in the pathogenesis of lymphoproliferative disorders likely exist. In large part, their recognition reflects further development and emergence of modern molecular biological methods that continue to refine classification of these complex disorders. In general, lymphomas of B-cell lineage affect the small intestine most commonly, while T-cell lymphomas are less common. Lymphomas are notoriously very heterogeneous $[26,27,28]$. Some may complicate well-defined celiac disease, but some may not [26,27]. For example, a natural killer cell form of T-cell lymphoma may occur in the intestine with a distinct immunophenotype. This entity is not known to be associated with celiac disease, progresses rapidly and has a poor prognosis $[29,30]$. In contrast, other rare peripheral T-cell types may occur with celiac disease, including a hepatosplenic form of gamma-delta T-cell lymphoma [31] or even T-cell type lymphomas in embryologically-related or gut-derived sites, including bronchopulmonary sites or the thyroid gland [32].

Recently, some novel lymphoproliferative disorders have been noted. For example, an indolent small intestinal form of CD4+ T-cell lymphoma was recently recognized, often in relatively young males with unique biological and clinical features, including histopathological changes mimicking or initially confused with celiac disease $[33,34,35,36]$. In a subsequent report, the apparently heterogeneous origin of this small intestinal CD4+ T-cell lymphoma was emphasized [18].

Another entity, large granular lymphocytic was also reported to complicate the clinical course of celiac disease $[37,38]$. Subsequently, 2 cases of celiac disease, reported to be initially responsive to gluten-free diets, were noted [39]. In both cases, sprue-like histopathological intestinal changes were present and clonal T-cell expansions, characteristic of large granular lymphocytic lymphoma, were shown in both small intestine and blood. Treatment for the leukemia with methotrexate and cyclosporine also resulted in a striking recovery of duodenal villous structure. The investigators suggested that IL-15 in the gut may be playing a role since IL-15 appears to play a critical role in the inflammatory process seen in celiac disease. Independent studies on the role of IL-15 in an animal model have been intriguing. Transgenic mice that overexpress IL-15 in enterocytes appear to develop a sprue-like small intestinal inflammatory process that can be reversed by antibody-mediated blockade of IL-15 [40]. Similar inhibition was noted in the same IL-15 transgenic mouse model with tofacitinib, a janus kinase inhibitor [41]. Although Phase 1 studies with a humanized monoclonal antibody agent in T-cell large granular lymphocytic leukemia failed to demonstrate a clinical hematologic response [42], future studies are anticipated that will further explore the role of such biological agents in treating some intestinal lymphomas.

\section{Conclusion and Future Issue}

Recurrent symptoms in well-established celiac disease may result in further clinical evaluation. In most, poor diet compliance is common. Other considerations include an unidentified gluten source, an erroneous initial diagnosis, another or second and superimposed cause for symptoms, or a complication, including collagenous sprue or an intestinal lymphoma. Failure to define an initial glutenfree diet response, however, suggests that celiac disease may not be present. Instead, a distinctive enteropathic process, refractory to diet restrictions, including gluten, is evident. This disorder seems to be distinct, but remains unclassified, and probably, represents a heterogeneous entity. Molecular changes suggestive of early clonal expansion of an aberrant population of intra-epithelial lymphocytes may be detected in some (with or without a prior gluten-free diet response), probably a signature of an early or "cryptic" lymphoma.

Treatment in this setting has proven to be exceedingly difficult. Mortality has been estimated to be approximately $50 \%$, especially in the first 2 to 5 years after first diagnosis. Most treatment studies are limited in numbers or reflect only anecdotal experience. Nutritional support, often with parenteral nutrition, is usually required. If the patient has confirmed celiac disease, then oral intake, if tolerated, should probably continue in the form of gluten-free food products. Steroids, including topical budesonide and immunosuppressants have been tried $[43,44]$. Some may show clinical improvement but histological changes are reported to be limited. Others have reported tioguanine (formerly, thioguanine) to be useful [45]. Use of monoclonal antibody agents, including infliximab and alemtuzumab have been noted in case reports $[46,47,48]$. Cladribine $[49,50]$ has been tried in some, but progression to overt lymphoma was noted. Autologous hematopoeitic stem-cell transplantation has been done in a few patients, but only with mixed results, especially if lymphoma is already present $[51,52]$. Further clinical study is needed, particularly to explore emerging molecular markers $[53,54,55,56,57]$ that may identify risk of progression to an overt lymphoproliferative disorder. Recent studies in an animal model of sprue-like intestinal disease with IL-15 blockade are particularly intriguing and should lead to added clinical trials of novel treatment agents in this complex group of disorders.

\section{References}

[1] Freeman. HJ, Chopra A, Clandinin MT, Thomson AB. Recent advances in celiac disease. World J Gastroenterol 2011; 17: 22592272.

[2] Gujral N, Freeman HJ, Thomson AB. Celiac disease: prevalence, diagnosis, pathogenesis and treatment. World J Gastroenterol 2012; 18: 6036-6059.

[3] Freeman HJ. Pearls and pitfalls in the diagnosis of adult celiac disease. Can J Gastroenterol 2008; 22: 273-280.

[4] MacDonald WC, Brandborg LL, Flick AL, Trier JS, Rubin CE. Studies of celiac sprue. IV. The response of the whole length of the small intestine to a gluten-free diet. Gastroenterology 1964; 47: 573-589. 
[5] Tursi A, Brandimarte G, Giorgetti GM, Elisei W, Inchingolo CD, Monardo E, Aiello F. Endoscopic and histologic findings in the duodenum of adults with celiac disease before and after changing to a gluten-free diet: a 2-year prospective study. Endoscopy 2006; 38: 702-707.

[6] Rubio-Tapia A, Ludvigsson JF, Brantner TL, Murray JA, Everhart JE. The prevalence of celiac disease in the United States. Am J Gastroenterol 2012; 107: 1538-1544.

[7] Freeman HJ. Detection of adult celiac disease using duodenal screening biopsies over a 30-year period. Can J Gastroenterol 2013; 27: 405-408.

[8] Freeman HJ. Sulindac-associated small bowel lesion. J Clin Gastroenterol 1986; 8: 569-571.

[9] Rubio-Tapia A, Herman ML, Ludvigsson JF, et al. Severe spruelike enteropathy associated with olmesartan. Mayo Clin Proc 2012; 87: 732-738.

[10] Gentile NM, D’Souza A, Fujii LL, Wu TT, Murray JA. Association between ipilimumab and celiac disease. Mayo Clin Proc 2013; 88: 414-417.

[11] Faulkner-Hogg KB, Selby WS, Loblay RH. Dietary analysis in symptomatic patients with coeliac disease on a gluten-free diet: the role of trace amounts of gluten and non-gluten food intolerances. Scand J Gastroenterol 1999; 34: 784-789.

[12] Hollon JR, Cureton PA, Martin ML, Puppa EL, Fasano A. Trace gluten contamination may play a role in mucosal and clinical recovery in a subgroup of diet-adherent non-responsive celiac disease patients. BMC Gastroenterol 2013; 13: 40.

[13] Schuffler MD, Chaffee RG. Small intestinal biopsy in a patient with Crohn's disease of the duodenum. The spectrum of abnormal findings in the absence of granulomas. Gastroenterology 1979; 76: 1009-1014.

[14] Freeman HJ. Collagenous colitis as the presenting manifestation of biopsy-defined celiac disease. J Clin Gastroenterol 2004; 38: 664668.

[15] Rubin CE, Eidelman S, Weinstein WM. Sprue by any other name. Gastroenterology 1970; 58: 409-413.

[16] Freeman HJ. Adult autoimmune enteropathy. World J Gastroenterol 2008; 14: 1156-1158.

[17] Malamut G, Verkarre V, Callens C, Colussi O, Rahmi G, MacIntyre E, Haioun C, Meresse B, Brousse N, Romana S, Hermine O, Cerf-Bensussan N, Cellier C. Enteropathy-associated T-cell lymphoma complicating an autoimmune enteropathy. Gastroenterology 2012; 142: 726-729.

[18] Malamut G, Meresse B, Kaltenbach S, Derrieux C, Verkarre V, Macintyre E, Ruskone-Fourmestraux A, Fabiani B, Radford-Weiss I, Brousse N, Hermine O, Cerf-Bensussan N, Cellier C. Small intestinal CD4+ T-cell lymphoma is a heterogeneous entity with common pathology features. Clin Gastroenterol Hepatol 2013; in press.

[19] Harris OD, Cooke WT, Thompson H, Waterhouse JA. Malignancy in adult celiac disease and idiopathic steatorrhea. Am J Med 1967; 42: 899-912.

[20] Freeman HJ, Weinstein WM, Shnitka TK, Piercey JR, Wensel RH. Primary abdominal lymphoma. Presenting manifestation of celiac sprue or complicating dermatitis herpetiformis. Am J Med 1977; 63: 585-594.

[21] Freeman HJ, Chiu BK. Multifocal small bowel lymphoma and latent celiac sprue. Gastroenterology 1986; 90: 1992-1997.

[22] Cellier C, Patey N, Mauvieux L, Jabri B, Delabesse E, Cervoni JP, Burtin ML, Guy-Grand D, Bouhnik Y, Modigliani R, Barbier JP, Macintyre E, Brousse N, Cerf-Bensussan N. Abnormal intestinal intraepithelial lymphocytes in refractory sprue. Gastroenterology 1998; 114: 471-481.

[23] Malamut G, Afchain P, Verkarre V, Lecomte $T$, Amiot A, Damotte D, Bouhnik Y, Colombel JF, Delchier JC, Allez M, Cosnes J, Lavergne-Slove A, Meresse B, Trinquart L, Macintyre E, Radford-Weiss I, Hermine O, Brousse N, Cerf-Bensussan N, Cellier C. Presentation and long-term follow-up of refractory celiac disease: comparison of type 1 with type II. Gastroenterology 2009; 136: 81-90.

[24] Freeman HJ. Free perforation due to intestinal lymphoma in biopsy-defined or suspected celiac disease. J Clin Gastroenterol 2003; 37: 299-302.

[25] Daum S, Weiss D, Hummel M, Ullrich R, Heise W, Stein H, Riecken EO, Foss HD; Intestinal Lymphoma Study Group. Frequency of clonal intra-epithelial T-lymphocyte proliferations in enteropathy-type intestinal T-cell lymphoma, celiac disease, and refractory sprue. Gut 2001; 49: 804-812.
[26] Freeman HJ. Lymphoproliferative and intestinal malignancies in 214 patients with biopsy-defined celiac disease. J Clin Gastroenterol 2004; 38: 429-434.

[27] Freeman HJ. Adult celiac disease and its malignant complications. Gut Liver 2009; 3: 237-246.

[28] Smedby KE, Akerman M, Hildebrand H, Glimelius B, Ekbom A, Askling J. Malignant lymphomas in coeliac disease: evidence of increased risks for lymphoma types other than enteropathy-type T cell lymphoma. Gut 2005; 54: 54-59.

[29] Yuan CM, Stein S, Glick JH, Wasik MA. Natural killer-like T-cell lymphoma of the small intestine with a distinct immunophenotype and lack of association with gluten-sensitive enteropathy. Arch Pathol Lab Med 2003; 127: e142-e146.

[30] Muram-Zborovski T, Loeb D, Sun T. Primary intestinal intraepithelial natural killer-like T-cell lymphoma: a case report of a distinct clinicopathological entity. Arch Pathol Lab Med 2009; 133: 133-137.

[31] Freeman HJ. Fulminant liver failure with necrotizing foci in the liver, spleen and lymph nodes in celiac disease due to malignant lymphoma. Can J Gastroenterol 1996; 10: 225-229.

[32] Freeman HJ. T-cell lymphoma of the thyroid gland in celiac disease. Can J Gastroenterol 2000; 14: 635-636.

[33] Carbonnel F, D’Almagne H, Lavergne A, Matuchansky C, Brouet JC, Sigaux F, Beaugerie L, Nemeth J, Coffin B, Cosnes J, Gendre JP, Rambaud JC. The clinicopathological features of an extensive small intestinal CD4 T-cell infiltration. Gut 1999; 45: 662-667.

[34] Zivny J, Banner BF, Agrawal S, Pihan G, Barnard GF. CD4+ Tcell lymphoproliferative disorder of the gut clinically mimicking celiac sprue. Dig Dis Sci 2004; 48: 551-555.

[35] Svrcek M, Garderet I, Sebbagh V, Rosenzwajg M, Parc Y, Lagrange M, Bennis M, Lavergne-Slove A, Flejou JF, Fabiani B. Small intestinal CD4+ T-cell lymphoma: a rare distinctive clinicopathological entity associated with prolonged survival. Virchows Arch 2007; 451: 1091-1093.

[36] Margolskee E, Jobanputra V, Lewis SK, Alobeid B, Green PH, Bhagat G. Indolent small intestinal CD4+ T-cell lymphoma is a distinct entity with unique biologic and clinical features. PLoS One 2013; 8: e68343.

[37] Lopez P, Morris DG, Galbraith PR, Lillicarp DP, Pross HF. Lymphoproliferative disease of "LAK cell" precursor large granular lymphocytes in association with celiac disease. Am J Hematol 1993; 43: 116-122.

[38] Molitor JL, Saint-Louis J, Louvet C, Vachon A, Vincent L, Beaulieu R. Large granular T-cell lymphocytic leukemia disclosed by bilateral uveitis: association with celiac disease. Rev Med Interne 1997; 18: 237-239.

[39] Malamut G, Meresse B, Verkarre V, Kaltenbach S, Montcuquet N, Duong Van Huyen J-P, Callens C, Lenglet J, Rahmi G, Samaha E, Ranque B, Macintyre E, Radford-Weiss I, Hermine O, CerfBensussan N, Cellier C. Large granular lymphocytic leukemia: a treatable form of refractory celiac disease. Gastroenterology 2012; 143: $1470-1472$.

[40] Yokoyama S, Watanabe N, Sato N, Perera PY, Filkoski L, Tanaka T, Miyasaka M, Waldman TA, Hiroi T, Perera LP. Antibodymediated blockade of IL-15 reverses the autoimmune intestinal damage in transgenic mice that overexpress IL-15 in enterocytes. Proc Natl Acad Sci USA 2009; 106: 15849-15854.

[41] Yokoyama S, Perera PY, Waldmann TA, Hiroi T, Perera LP. Tofacitinib, a janus kinase inhibitor demonstrates efficacy in an IL-15 transgenic mouse model that recapitulates pathologic manifestations of celiac disease. J Clin Immunol 2013; 33: 586-594.

[42] Waldmann TA, Conlon KC, Stewart DM, Worthy TA, Janik JE, Fleisher TA, Albert PS, Figg WD, Spencer SD, Raffeld M, Decker JR, Goldman CK, Bryant BR, Petrus MN, Creekmore SP, Morris JC. Phase 1 trial of IL-15 trans presentation blockade using humanized MikB1 mAb in patients with T-cell large granular lymphocytic leukemia. Blood 2013; 121: 476-484.

[43] Brar P, Lee S, Lewis S, Egbuna I, Bhagat G, Green PH. Budesonide in the treatment of refractory celiac disease. Am J Gastroenterol 2007; 102: 2265-2269.

[44] Goerres MS, Meijer JW, Wahab PJ, Kerckhaert JA, Groenen PJ, van Krieken $\mathrm{JH}$, Mulder CJ. Azathioprine and prednisone combination therapy in refractory coeliac disease. Alim Pharm Ther 2003; 18: 487-494.

[45] Tack GJ, van Asseldonk DP, van Wanrooij RL, van Bodegraven AA, Mulder CJ. Tioguanine in the treatment of refractory coeliac disease - a single center experience. Aliment Pharm Ther 2012; 36 : 274-281. 
[46] Gillett HR, Arnott ID, McIntyre M, Campbell S, Dahele A, Priest M, Jackson R, Ghosh S. Successful infliximab treatment for steroid-refractory celiac disease: a case report. Gastroenterology 2002; 122: 800-805.

[47] Constantino G, della Torre A, Lo Presti MA, Caruso R, Mazzon E, Fries $\mathrm{W}$. Treatment of life-threatening type 1 refractory coeliac disease with long-term infliximab. Dig Liver Dis 2008; 40: 74-77.

[48] Vivas S, Ruiz de Morales JM, Ramos F, Suarez-Vilela D. Alemtuzumab for refractory celiac disease in a patient at risk for enteropathy-associated T-cell lymphoma. N Engl J Med 2006; 354: 2514-2515.

[49] Tack GJ, Verbeek WH, Al-Toma A, Kuik DJ, Schreurs MW, Visser O, Mulder CJ. Evaluation of cladribine treatment in refractory celiac disease type II. World J Gastroenterol 2011;17: 506-513.

[50] Al-Toma A, Goerres MS, Meijer JW. Cladribine therapy in refractory celiac disease with aberrant T cells. Clin Gastroenterol Hepatol 2006; 4: 1322-1327.

[51] Tack GJ, Wondergem MJ, Al-Toma A, Verbeek WH, Schmittel A, Machado MV, Perri F, Ossenkoppele GJ, Huijgens PC, Schreurs MW, Mulder CJ, Visser OJ. Auto-SCT in refractory celiac disease type II patients unresponsive to cladribine therapy. Bone Marrow Transplant 2011; 46: 840-846.

[52] Al-Toma A, Visser OJ, van Roessel HM, von Blomberg BM, Verbeek WH, Scholten PE, Ossenkoppele GJ, Huijgens PC, Mulder CJ. Autologous hematopoietic stem cell transplantation in refractory celiac disease with aberrant T cells. Blood 2007; 109: 2243-2249.

[53] Tack GJ, van Wanrooij RL, Von Blomberg BM, Amini H, Coupe VM, Bonnet P, Mulder CJ, Schreurs MW. Serum parameters in the spectrum of celiac disease: beyond standard antibody testinga cohort study. BMC Gastroenterol 2012; 12: 159.

[54] De Nitto D, Monteleone I, Franze E, Pallone F, Monteleone G. Involvement of interleukin-15 and interleukin-21, two gammachain-related cytokines, in celiac disease. World J Gastroenterol 2009; 15: 4609-4614.

[55] Malamut G, El Machhour R, Montcuquet N, Martin-Lanneree S, Dusanter-Fourt I, Verkarre V, Mention JJ, Rahmi G, Kiyone H, Butz EA, Brousse N, Cellier C, Cerf-Bensussan N, Meresse B. IL15 triggers an antiapoptotic pathway in human intraepithelial lymphocytes that is a potential new target in celiac diseaseassociated inflammation and lymphomagenesis. J Clin Invest 2010 120: 2131-2143.

[56] Schmitz F, Tjon JM, Lai Y, Thompson A, Kooy-Winkelaar Y, Lemmers RJ, Verspaget HW, Mearin ML, Staal FJ, Schreurs MW, Cupedo T, Langerak AW, Mulder CJ, van Bergen J, Koning F. Identification of a potential physiological precursor of aberrant cells in refractory coeliac disease type II. Gut 2013; 62: 509-519.

[57] Zevallos VF, Schuppan D. Refractory celiac disease: one step closer to the origin of aberrant lymphocytes. Gut 2013; 62: 485486. 